\title{
Reforma trabalhista e trabalho digno: uma combinação possível?
}

\author{
Labor reform and dignified work: a possible combination?
}

\author{
Maritânia Salete Salvi RAFAGNIN* \\ iltps://orcid.org/o00o-0003-0120-522X
}

\author{
Vera Maria Ribeiro NOGUEIRA** \\ https://orcid.org/oooo-0003-4158-1510
}

\begin{abstract}
Resumo: Neste artigo, faz-se uma comparação entre alguns aspectos da Reforma Trabalhista de 2017 e o conceito de trabalho digno. Parte-se do suposto enunciado pelo governo federal e veiculado pela mídia e elites econômicas da relevância da reforma para a integração do Brasil à dinâmica de reprodução do capital no século XXI. Através da pesquisa documental, analisam-se da Lei no 13.467/2017, os arts. 223-G; 611-A; 611-B; 582 e 507-B; e a terceirização irrestrita da Lei no 13.429/2017, confrontando esses dispositivos, posteriormente, com o conceito de trabalho digno. Os resultados apontam para a incompatibilidade das normas com referido conceito. À guisa de conclusão, evidencia-se como a desregulamentação e a flexibilização dos artigos analisados compõem o processo de desmonte dos direitos laborais previstos pelo modelo neoliberal, implicando novas morfologias da precarização do trabalho.
\end{abstract}

Palavras-chave: Reforma Trabalhista. Trabalho digno. Precarização do trabalho.

\begin{abstract}
This article compares some aspects of the 2017 Labor Reform with the concept of decent work. It starts from the statement made by the federal government and disseminated by the media and economic elites regarding the relevance of the reform for the integration of Brazil into the reproductive dynamics of capital in the 21st century. Through documentary research, articles 223-G; 611-A; 611-B; 582 and 507-B of Law no. 13,467/2017 are analyzed, as well as the unrestricted outsourcing contained in Law no. 13,429/2017, juxtaposing these devices with the concept of dignified work. The results point to the incompatibility of the rules with this concept. In conclusion, it is evident that the deregulation and flexibilisation within the analyzed articles form a process of the dismantling the labor rights established by the neoliberal model, implying new morphologies in labor precariousness.
\end{abstract}

Keywords: Labor Reform. Dignified work. Labor precariousness.

Submetido em: 12/3/2020. Revisado em: 15/6/2020; 30/9/2020. Aceito em: 7/12/2020.

\footnotetext{
${ }^{*}$ Contadora. Mestra em Política Social. Doutoranda em Política Social e Direitos Humanos pela Universidade Católica de Pelotas (UCPel). Bolsista CAPES. Universidade Católica de Pelotas (UCPel, Pelotas, Brasil). Rua Gonçalves Chaves, no 373, Centro, Pelotas (RS), CEP: 96015-560. E-mail: mari.salvi@gmail.com.

** Assistente Social. Doutora em Enfermagem. Professora do Programa de Pós-Graduação em Política Social e Direitos Humanos da Universidade Católica de Pelotas (UCPel) e do Programa de Pós-Graduação em Serviço Social da Universidade Federal de Santa Catarina (UFSC). Universidade Católica de Pelotas (UCPel, Pelotas, Brasil). Rua Gonçalves Chaves, no 373, Centro, Pelotas (RS), CEP: 96015-56o. E-mail: veramrn@gmail.com.

(cc)) $\mathrm{Br}$ (C) A(s) Autora(s)/O(s) Autor(es). 2019 Acesso Aberto Esta obra está licenciada sob os termos da Licença Creative Commons Atribuição 4.0 Internacional (https://creativecommons.org/licenses/by/4.o/deed.pt_BR), que permite copiar e redistribuir o material em qualquer suporte ou formato, bem como adaptar, transformar e criar a partir deste material para qualquer fim, mesmo que comercial. O licenciante não pode revogar estes direitos desde que você respeite os termos da licença.
}

Argum., Vitória, v. 13, n. 1, p. 153-166, jan./abr. 2021. | ISSN 2176-9575 


\section{Introdução}

A Reforma Trabalhista (RT), introduzida no ordenamento jurídico através das Leis $\mathbf{n}^{\mathbf{0}^{\mathbf{s}}}$ 13.467/2017 (BRASIL, 2017a) e 13.429/2017 (BRASIL, 2017b), veio a alterar os aspectos estruturais do Direito do Trabalho, dentre esses, a gestão da força de trabalho. $\mathrm{O}$ argumento esgrimido pelos seus defensores é ser a Consolidação das Leis do Trabalho (CLT) um obstáculo ao desenvolvimento do capitalismo integrado ao mercado internacional (MARQUES; UGINO; 2017), não colocando em debate os reais beneficiários dessa alteração.

Parte-se do pressuposto de que tanto a Lei no 13.467/2017 como a Lei no 13.429/2017 são apresentadas pelo poder público e as elites econômicas como estratégias de desregulamentação e flexibilização dos direitos laborais, necessárias para a integração do Brasil à dinâmica de reprodução do capital no século XXI. Contrapondo-se a essa argumentação, este artigo objetiva comparar alguns dos principais artigos da RT, no contexto de precarização do trabalho no capitalismo contemporâneo, com o conceito de trabalho digno.

Acerca do trabalho digno, sua garantia se dá pelos organismos internacionais de direitos humanos e nas convenções da Organização Internacional do Trabalho (OIT), ratificadas pelo país. Em nível constitucional, relaciona-se diretamente com o princípio e valor fundamental da dignidade humana, contido no art. 1o, inciso III, da Constituição Federal (CF) (BRASIL, 1988). Trata-se do direito de todas as pessoas deterem condições laborais justas e favoráveis para garantia de uma vida com dignidade (DELGADO, 2015).

Apesar de a RT de 2017 ter alterado mais de 100 artigos da CLT, para delimitar o objeto deste estudo, foram selecionados os que apresentaram algumas das principais alterações. $\mathrm{O}$ critério de escolha deu-se em face do impacto direto no cotidiano dos trabalhadores e por serem antagônicos aos preceitos do trabalho digno. Assim, não se pretende uma análise exaustiva das normativas, mas discutir questões relevantes para apreciação do objetivo deste artigo.

Utilizando-se da pesquisa documental, analisa-se da Lei no 13.467/2017, o art. 223-G, tratando sobre o teto máximo dos passivos trabalhistas; o art. 611-B, no que dispõe sobre a exclusão das regras de duração do trabalho e dos intervalos para a consideração destes nas normas de saúde, higiene e segurança do trabalho; o art. 611-A, abordando a supremacia dos acordos coletivos e convenções coletivas de trabalho sobre o legislado; o art. 582, versando sobre o fim da obrigatoriedade da contribuição sindical; e o art. 507-B, dispondo sobre a possibilidade de assinatura anual do termo de quitação das obrigações trabalhistas. Ainda, da Lei no 13.429/2017, é debatida a terceirização irrestrita.

$\mathrm{O}$ artigo encontra-se estruturado em três partes. A primeira parte é destinada a discutir o contexto de precarização do trabalho a partir de 1970, entendendo os traços gerais que assume a gestão da força de trabalho com o advento da financeirização do capital e da reestruturação produtiva nos marcos da ordem neoliberal. Na segunda parte, aprofundam-se os pontos selecionados da RT de 2017, com vistas a apreender como influenciam nas condições do e no trabalho. Por fim, na terceira parte, realiza-se a comparação entre os dispositivos citados com o conceito de trabalho digno. 


\section{Contexto de precarização do trabalho}

As mutações ocorridas no capitalismo contemporâneo a partir das três últimas décadas do século XX impactaram profundamente o mundo do trabalho, pois, conforme Mészáros (2002) e Antunes (2018), os anos de 1970 foram marcados pela estagnação e crise do regime de acumulação taylorista/fordista, que possuía determinações mais profundas relacionadas à própria estrutura do capital.

Em resposta à crise, Marques e Ugino (2017) destacam a mudança do capital industrial para o capital financeiro, que, de acordo com Chesnais (2005), teve três aspectos centrais: a) desregulamentação monetária e financeira; b) descompartimentação dos mercados financeiros nacionais; e c) desintermediação das operações de empréstimos a todos os tipos de investidores institucionais. Também foi necessária a desregulamentação de todos os mercados, dentre eles, o mercado de trabalho. Com essas medidas, o capital internacional passou a ter seu fluxo livre, intervindo tanto mundialmente como no interior dos países.

Essa situação implicou uma nova divisão internacional do trabalho, afinal, dada a liberdade alcançada por meio da financeirização, alterou-se a maneira da gestão da força de trabalho. Com a lógica imediatista dos acionistas para obtenção de lucros, somaram-se os interesses da alta gerência, e tanto o emprego como a renda dos trabalhadores sofreram impactos negativos, tais como: "[...] a competição intraclasse, a flexibilização, a desregulamentação dos mercados financeiro e trabalhista, e o livre fluxo de capitais" (PEREIRA, 2017, p. 25).

No Brasil, a submissão ao capitalismo financeiro teve seu início na década de 1990, implicando transformações acentuadas no país, pois, segundo Antunes e Praun (2015), estas tinham como ponto inicial a dinâmica de um país com exploração dependente, fundado na superexploração da força de trabalho.

Acerca do conceito de dependência, Ruy Mauro Marini (1973) esclarece que se trata de uma relação de subordinação entre nações formalmente independentes, cujas relações são estabelecidas a fim de assegurar a reprodução ampliada da dependência. Destarte, conforme o autor, o problema da troca desigual para a América Latina não é o de compensar uma perda de mais-valia, que é incapaz de evitá-la no nível das relações de mercado internacional. A reação da economia dependente é compensá-la na produção interna. Assim, o aumento da intensidade do trabalho surge como um aumento da mais-valia, conseguido através da maior exploração do trabalhador, e não pelo aumento da sua capacidade produtiva (MARINI, 1973). É a partir desse cenário que ocorrem as transformações da década de 1990, com a reestruturação produtiva nos marcos do neoliberalismo.

As transformações neoliberais, ocorridas desde 1990, tinham como finalidade “[...] reconstruir o Estado capitalista a serviço da nova lógica do capitalismo mundial" (ALVES, 2000, p. 114) por meio da: liberalização comercial, do processo de privatizações, da reestruturação das políticas sociais, da desregulamentação e flexibilização das relações trabalhistas, da austeridade nos gastos públicos, dentre outros (ALVES, 2000).

No Brasil, a adesão a esse modelo, sistematizado pelo Consenso de Washington, foi gradual, pois, embora já na década de 1990 o governo Collor de Mello tenha aderido ao projeto neoliberal, sua implementação diminui durante o governo de Itamar Franco (1993/1994) “[...]

Argum., Vitória, v. 13, n. 1, p. 153-166, jan./abr. 2021. | ISSN 2176-9575 
sendo retomado posteriormente com toda a força, e amplamente executado, pelos dois governos de Fernando Henrique Cardoso (1995/2002)" (FILGUEIRAS, 2003, p. 1).

Durante os governos dos presidentes Luís Inácio Lula da Silva (2003/2010) e Dilma Rousseff (2011/2016), esse processo de adesão foi atenuado, pois tiveram uma trajetória neoliberal relativamente distinta do governo anterior (RAFAGNIN, T., 2019). Apesar da melhoria dos indicadores sociais, principalmente, em função de programas de transferência de renda para as camadas mais pobres, não significou uma mudança substancial durante esses 12 anos de governo, uma vez que o Brasil seguiu como um dos países do mundo com maiores índices de concentração de renda (TENEMBLAT, 2014).

Entretanto, no cenário mundial, a partir de 2008, teve início uma crise do capitalismo que impactou diretamente o Brasil a partir de 2014 (SILVA, 2019). Como resultado, em busca da retomada das taxas de lucro, no governo de Michel Temer (2016/2017) inicia-se "[...] a aprovação de legislações voltadas para a retirada dos direitos dos trabalhadores, o congelamento dos investimentos sociais, o privilegiamento do capital financeiro no orçamento da União, e a inserção subordinada e dependente do Brasil na economia mundial" (SILVA, 2019, p. 253).

A partir de então, tem-se a retomada das políticas liberalizantes, tendo como marco o processo analisado por Thiago Rafagnin (2019) como o aprofundamento do neoliberalismo, o qual ocorre por meio: a) do corte das despesas públicas primárias - com a Emenda Constitucional no 95; b) da RT, através da Lei no 13.467, de 13 de julho de 2017, e da terceirização irrestrita pela Lei no 13.429, de 31 de março de 2017; e c) da Reforma da Previdência ${ }^{1}$.

Verifica-se, portanto, estar a RT estreitamente alinhada a um pacote de medidas visando assegurar o aprofundamento do modelo neoliberal no Brasil e que, no contexto atual, tratase de mais uma das expressões de precarização do trabalho - fenômeno esse, conforme Antunes (2018), intrínseco à sociabilidade construída sob o signo do capital e que pode ser mais ou menos intenso, a depender do processo de exploração do trabalho nas distintas etapas do capitalismo.

\section{Uma breve discussão da Reforma Trabalhista de 2017}

Mesmo que os processos de precarização da força de trabalho tenham se intensificado a partir da década de 1990, após a crise no contexto brasileiro iniciada em 2014, foi retomado o discurso sobre a necessidade de flexibilizar as leis laborais com intuito de modernizar as relações de trabalho. Nesse cenário, a CLT passou a ser identificada como o "[...] obstáculo maior ao desenvolvimento do capitalismo integrado ao mercado internacional” (MARQUES; UGINO, 2017, p. 9).

Alterando 117 artigos e 200 dispositivos da CLT, a RT de 2017 teve como objetivo "flexibilizar" o mercado de trabalho sob o pretexto de o país tornar-se atrativo aos investidores

\footnotetext{
${ }_{1}^{1}$ Prevista no Plano de Governo do ex-presidente Michel Temer (2016-2018), intitulado Uma ponte para o futuro (RAFAGNIN, 2019) e aprovada no governo do presidente Jair Bolsonaro, em 12 de novembro de 2019.
}

Argum., Vitória, v. 13, n. 1, p. 153-166, jan./abr. 2021. | ISSN 2176-9575 
internacionais, estimulando a criação de novos postos de trabalho e combatendo a informalidade (SCHERER; DILIGENTI; ARAÚJO, 2019). Fato que, após a sua aprovação, não foi comprovado, pois, conforme Lameiras et al. (2019), o número de desempregados há mais de dois anos nessa situação aumentou um correspondente de 3,3 milhões de pessoas entre o período do primeiro trimestre de 2015, que era de 17,4\%, e o mesmo período de 2019 , avançando para $24,8 \%$.

Contudo, antes de tratar dos aspectos da RT de 2017, deve-se observar, segundo Marques e Ugino (2017), que o mercado de trabalho no Brasil sempre foi dividido em dois segmentos: o formal (direitos trabalhistas e previdenciários garantidos) e o informal (salários, jornada e condições laborais sem amparo legal e sem acesso aos benefícios previdenciários), distribuído com cerca de 50\% para cada segmento, visto que somente uma parcela de trabalhadores consegue migrar para o mercado formal. Conforme as autoras, tal percentual de postos de trabalho informais é reduzido durante os governos Lula e Dilma, e torna a aumentar com a recente crise no país.

Ademais, outra questão relevante a ser considerada é a qualidade dos postos de trabalho criados entre 2004 a 2010, relacionada ao nível salarial do mercado de trabalho formal, afinal, dos 2,1 milhões de postos criados por ano, cerca de 2 milhões de trabalhadores ganhavam até 1,5 salário mínimo (BRAGA, 2017). Portanto, tem-se mais um desdobramento da precarização, já que os contratos de trabalho criados privilegiaram a oferta de mão de obra não qualificada.

É nesse cenário, já precarizado, que se insere o discurso da ampliação da flexibilização e desregulamentação das leis trabalhistas. Daí a importância de se abordar alguns questionamentos legais e constitucionais introduzidos por meio das Leis $n^{\mathbf{0}^{\mathrm{S}}}$ 13.467/2017 e 13.429/2017, porquanto, o discurso preconizado pela necessidade de atualizar a legislação ${ }^{2}$, na verdade, trata-se de uma medida de retirada de direitos da classe trabalhadora.

Como primeiro ponto a ser destacado da RT, tem-se a imposição do teto máximo para pagamento de passivos laborais. Anteriormente, o cumprimento da lei gerava um passivo muitas vezes imprevisível, podendo alcançar valores elevados. Agora, segundo o art. 223-G, $\S 1^{-}$, esse passivo é de, no máximo, 50 vezes o último salário contratual do ofendido (BRASIL, 2017a). Logo, esse custo, em caso de danos extrapatrimoniais, passa a ser calculável e sujeito a um limite prefixado. Também, de acordo com o disposto no art. 223-G, $\S$ 1ㅜㅡ, é vedada a acumulação de indenização por diferentes ofensas, tendo-se, então, estipulado o máximo de custos que podem incorrer sobre uma mesma demanda.

Ademais, com a RT, segundo o caput do art. 611-A, foi estabelecida a supremacia das cláusulas de convenção coletiva e acordo coletivo de trabalho acerca de temas estratégicos relativos aos contratos de trabalho, os quais impactam, inclusive, a saúde dos trabalhadores (RAFAGNIN, M., 2019). Contudo, ao mesmo tempo que se estipula um peso considerável para as negociações coletivas, a RT aborda vários pontos que vêm a enfraquecer o poder de

\footnotetext{
${ }_{2}$ Para uma análise mais aprofundada da mudança na legislação, ver Departamento Intersindical de Estatísticas e Estudos Socioeconômicos (DEPARTAMENTO INTERSINDICAL DE ESTATÍSTICA E ESTUDOS SOCIOECONÔMICOS, 2017).
} 
negociação dos trabalhadores e sindicatos (CARVALHO, 2017), como no art. $582,{ }^{3}$ que determina o fim da obrigatoriedade da contribuição sindical, além da abertura da possibilidade de muitos acordos serem estabelecidos entre empregador e empregado (RAFAGNIN, M., 2019). Acerca dessa questão, assevera Lourenço (2018) que os trabalhadores irão se submeter com maior facilidade às diligências do empregador, abrindo possibilidade para negociações até inferiores ao que consta na legislação.

Ainda, no art. 507-B ${ }^{4}$, a RT prevê a possibilidade de assinatura do termo de quitação anual de obrigações trabalhistas. Após assinado esse termo, caso o trabalhador identifique possíveis descumprimentos do empregador, está impedido de recorrer à Justiça para cobrálos, afinal, assinou a declaração de quitação. Logo, retira-se a possibilidade de o trabalhador ter direitos acumulados.

No art. 611-B ${ }^{5}$ da RT, é estabelecido, dentre o rol de objeto ilícito de convenção coletiva ou de acordo coletivo de trabalho, em seu inciso XVII, as normas de saúde, higiene e segurança do trabalho previstas em lei ou em normas regulamentadoras do Ministério do Trabalho (BRASIL, 2017a). Já em seu parágrafo único, dispõe que as regras sobre duração do trabalho e intervalos não são consideradas como normas de saúde, higiene e segurança do trabalho. Contudo, conforme a Convenção 155 da OIT, sobre Saúde e Segurança no Trabalho, tanto o tempo de trabalho como o intervalo são fatores determinantes para a qualidade de vida no labor (SCALÉRCIO; MINTO, 2016); portanto, a não atenção a esses fatores pode resultar em agravantes de precarização do trabalho.

Por fim, destaca-se a terceirização, antes permitida apenas para atividades-meio. Com a Lei no 13.429/2017, passou a ser liberada também para as atividades-fim. Acerca do tema, Antunes (2018) assinala ser a principal justificativa de as empresas terceirizarem, a possibilidade de transferência de "[...] riscos para os trabalhadores, desobrigando-se de cumprir e seguir as exigências da legislação e dos direitos trabalhistas, que se tornam de responsabilidade das terceirizadas" (ANTUNES, 2018, p. 150). Assim, de acordo com o autor, a terceirização é um dos elementos de ampliação significativa dos índices de acidentes laborais, nos mais distintos ramos, setores e espaços de trabalho.

As indicações acima evidenciam como as mudanças relativas a desregulamentação e flexibilização dos direitos trabalhistas, aprovadas no ano de 2017, afetam diretamente o mercado de trabalho no país, pois, segundo Silva (2019) “[...] ao contrário dos discursos oficiais e classistas nutridos pelo pensamento econômico liberal, o que se manifestou no

\footnotetext{
3 “Art. 582. Os empregadores são obrigados a descontar da folha de pagamento de seus empregados relativa ao mês de março de cada ano a contribuição sindical dos empregados que autorizaram prévia e expressamente o seu recolhimento aos respectivos sindicatos" (BRASIL, 2017a).

4 “Art. 507-B. É facultado a empregados e empregadores, na vigência ou não do contrato de emprego, firmar o termo de quitação anual de obrigações trabalhistas, perante o sindicato dos empregados da categoria.

Parágrafo único. O termo discriminará as obrigações de dar e fazer cumpridas mensalmente e dele constará a quitação anual dada pelo empregado, com eficácia liberatória das parcelas nele especificadas" (BRASIL, 2017a).

5 "Art. 611-B. Constituem objeto ilícito de convenção coletiva ou de acordo coletivo de trabalho, exclusivamente, a supressão ou a redução dos seguintes direitos: [...] XVII - normas de saúde, higiene e segurança do trabalho previstas em lei ou em normas regulamentadoras do Ministério do Trabalho" (BRASIL, 2017a).
} 
Brasil [com a RT] foi o aumento do trabalho precário, do desemprego, das desigualdades sociais" (SILVA, 2019, p. 258).

\section{Reforma Trabalhista e trabalho digno}

Embora a RT tenha sido veiculada na mídia e aprovada pelo Congresso Nacional com o discurso sobre a exigência de reformulação do Direito do Trabalho, visando a criação de novos postos laborais, as evidências apontam ser seu alvo principal a desregulamentação e flexibilização dos direitos, e sempre em benefício do empregador.

Nesse sentido, deve-se esclarecer a distinção entre desregulamentação e flexibilização. Conforme Delgado (2015), a primeira refere-se a um "[...] o fenômeno abarcado pelo neoliberalismo, fundado na subsistência de um Estado mínimo, que exige que o Estado deixe de regular questões sociais, inclusive as de cunho trabalhista, em prol da regulação autônoma privada, individual ou coletiva" (DELGADO, 2015, p. 172). Já a flexibilização dos direitos laborais "[...] perfaz-se, na realidade brasileira, pela atuação do suposto rigor e imperatividade das normas jurídicas, mediante negociação coletiva. É um fenômeno jurídico mais maleável sob o ponto de vista dos contratantes trabalhistas, em especial do empregador" (DELGADO, 2015, p. 173).

Logo, tanto a flexibilização como a desregulamentação são mecanismos de redução de direitos e de precarização do labor, as quais atuam em benefício dos empregadores. Tais traços têm sido a marca da gestão da força de trabalho no modelo neoliberal, como observados nos artigos discutidos no tópico anterior: limitação do passivo trabalhista (art. 223-G); a prevalência do acordado sobre o legislado (art. 611-A); a possibilidade de assinatura do termo de quitação das obrigações trabalhistas (art. 507-B); e o fim da obrigatoriedade da contribuição sindical (art. 582).

Na contramão desse ideário, tem-se o conceito de trabalho digno, garantido através dos instrumentos internacionais de direitos humanos e nas convenções internacionais da OIT, ratificadas pelo país (DELGADO, 2015), como um “[...] patamar civilizatório universal de direitos para o ser humano trabalhador, reconhecendo o direito de toda pessoa gozar de condições de trabalho justas e favoráveis para que possa levar uma vida digna" (DELGADO, 2015, p. 189).

A partir dessa conceituação, verifica-se que trabalho digno se relaciona diretamente ao princípio e valor fundamental da dignidade humana, contido no art. $\mathbf{1}^{\mathbf{o}}$, inciso III da CF (BRASIL, 1988), dado que o Estado “[...] existe em função da pessoa humana, e não o contrário, já que o ser humano constitui a finalidade precípua, e não o meio da atividade estatal" (SARLET, 2015, p. 78).

Deste modo, cabe ao Estado, pela via normativa, proteger a dignidade de seus cidadãos, e, "[...] nas relações sociais, onde se destacam as trabalhistas, deve ser vedada a violação da dignidade, o que significa que o ser humano jamais poderá ser utilizado como objeto ou meio para realização do querer alheio" (DELGADO, 2015, p. 180). Portanto, o sistema de valores que orienta o Estado democrático de direito não pode ser adaptável à lógica do mercado e ao modo de produção capitalista (ROSENFIELD; PAULI, 2012). 
Assim, para que o trabalho seja digno, deve ser adequadamente remunerado, promovendo a existência do trabalhador e de sua família; exercido em condições de equidade, segurança e de higiene, com direitos a períodos de descanso e lazer; de limitação das horas diárias e semanais; remunerado em feriados e com direitos a greve e a livre associação sindical (DELGADO, 2015; ROSENFIELD; PAULI, 2012).

Do exposto, verifica-se que os aspectos analisados nas Lei $\mathrm{n}^{\mathrm{o}}{ }^{\mathrm{s}}$ 13.467/2017 e 13.429/2017 seguem uma direção inversa ao conceito de trabalho digno e até ao disposto na própria $\mathrm{CF}$, representando um retrocesso em termos de direitos.

Conforme é possível observar, quando estabelecida uma indenização proporcional à remuneração do trabalhador, fere-se a atenção à equidade, afinal, nas organizações, os distintos trabalhadores recebem remunerações diferentes, de acordo com suas funções, tempo de empresa, qualificação profissional etc. Ademais, em pesquisa divulgada pelo DIEESE (DEPARTAMENTO INTERSINDICAL DE ESTATÍSTICAS E ESTUDOS SOCIOECONÔMICOS, 2013), as mulheres percebem rendimentos menores do que os homens e, segundo Coutinho (2006), devido às suas responsabilidades com a família e a maternidade, são alvo de condutas discriminatórias nas empresas, conhecidas como assédio moral laboral. Logo, essas trabalhadoras, além de normalmente receber salários inferiores, quando vítimas de assédio, receberão uma indenização menor.

Ainda, com a RT, as empresas passaram a ter a possibilidade de assinatura do termo de quitação das obrigações trabalhistas anualmente, fazendo com que os trabalhadores abram mão de seus direitos. Na verdade, esse termo reforça apenas a relação de exploração do trabalhador pelo seu empregador, porquanto, ao assiná-lo, declara que a empresa cumpriu com todas as obrigações legais, quando, na realidade, podem não estar sendo atendidas. Isso porque, antes de fazer uma reivindicação na justiça, o trabalhador vai preferir manter sua fonte de renda, submetendo-se, portanto, à vontade de seu patrão; afinal, a relação existente entre ambos é de hipossuficiência.

Além do mais, ao liberar a prevalência do negociado sobre o legislado, permitem-se acordos até mesmo inferiores ao disposto na legislação trabalhista. Essa questão deve ser analisada juntamente com a extinção da contribuição obrigatória sindical, uma vez que, por um lado, a lei continua assegurando a livre associação dos trabalhadores, mas, por outro, elimina a contribuição obrigatória, reduzindo o poder de barganha dos representantes sindicais, que sofrem, a cada dia mais, com seu enfraquecimento.

Também, os artigos 611-A e 611-B vão contra o disposto na Convenção da OIT 98 - Direito de Sindicalização e de Negociação Coletiva ${ }^{6}$. A respeito disso, a OIT solicitou que o governo examinasse, em consulta aos sindicatos, a revisão desses dispositivos, a fim de as tornar em conformidade com a Convenção 98 (INTERNATIONAL LABOUR OFFICE, 2018). Numa carta de resposta à OIT, o governo brasileiro garantiu que não violou "qualquer convenção" e que apenas "modernizou" a legislação. Em outro trecho do comunicado, avisou a não aceitação que assuntos domésticos fossem levados em consideração pela organização, ao avaliar as leis trabalhistas, remetendo a uma suposta interferência da entidade em temas

${ }^{6}$ Ratificada pelo Brasil em 18 de novembro de 1952. 
políticos nacionais (CHADE, 2019). Como resultado disso, a OIT decidiu manter o Brasil na lista dos países que estão sendo monitorados por violarem as convenções (OLIVEIRA; D'AGOSTINO, 2019).

Acerca do assunto, é preciso esclarecer que os tratados e convenções no ordenamento jurídico, mesmo quando não ratificados pelo país nos termos do art. $5^{\circ}$, $\S 3^{\mathrm{o}^{7}}$, da $\mathrm{CF}$, assumem condição supralegal ${ }^{8}$, ou seja, em termos hierárquicos, estão abaixo da Constituição, mas acima de todas as demais normas infraconstitucionais. Logo, os artigos 611-A e 611-B precisariam ter sido submetidos a um controle de convencionalidade, os quais, dada sua incompatibilidade com o ordenamento jurídico, deveriam ser suprimidos.

Também, do art. 611-B, deve-se analisar outro ponto polêmico, o qual declara que se constituem objeto ilícito de convenção ou de acordo coletivo de trabalho, a supressão ou a redução de direitos, dentre esses, do inciso XVII, as normas de saúde, higiene e segurança do trabalho previstas em lei ou em normas regulamentadoras do Ministério do Trabalho (BRASIL, 2017a). Já, no parágrafo único, dispõe que as regras sobre duração do trabalho e intervalos não são consideradas como normas de saúde, higiene e segurança do trabalho (BRASIL, 2017a). Tal modificação vai contra a Convenção da OIT 155 - Segurança e Saúde dos Trabalhadores ${ }^{9}$, pois, em seu art. $5^{\circ}$, alínea b, estabelece, o tempo/duração do trabalho como um dos fatores que afetam a saúde e segurança no trabalho, e no art. $7^{\circ}$ dispõe sobre a necessidade de intervalos adequados para a saúde e segurança no trabalho (SCALÉRCIO, MINTO, 2016).

Ainda, para análise, deve-se considerar, conforme estabelece a CF no art. 6o, que a saúde é um direito fundamental social, e a saúde do trabalhador, por ser espécie desta, também deve ser assegurada. Outrossim, no art. $7^{-}$, inciso XXII, dispõe que, dentre os direitos dos trabalhadores urbanos e rurais, que visem a melhoria da sua condição social, estão a redução dos riscos inerentes ao trabalho, por meio de normas de saúde, higiene e segurança (BRASIL, 1988).

Ainda, conforme disposto no art. $3^{\circ}$, alínea e, da Convenção 155, “[...] o termo saúde com relação ao trabalho abrange não só a ausência de afecções ou de doenças, mas também os elementos físicos e mentais que afetam a saúde e estão diretamente relacionados com a segurança e a higiene no trabalho" (SCALÉRCIO; MINTO, 2016, p. 159). Desse modo, fatores como o tempo de trabalho, intensidade, jornada e intervalos interferem diretamente na saúde e segurança do trabalhador. Portanto, afirma-se que o parágrafo único do art. 611-B, deveria ser suprimido, dada a sua incompatibilidade com a Convenção 155. Também é possível concluir sobre a sua inconstitucionalidade, por ser contrário ao direito fundamental à saúde do trabalhador.

\footnotetext{
7 "Art. $5^{\mathrm{o}} \S 3^{\mathrm{o}}$ Os tratados e convenções internacionais sobre direitos humanos que forem aprovados, em cada Casa do Congresso Nacional, em dois turnos, por três quintos dos votos dos respectivos membros, serão equivalentes às emendas constitucionais” (BRASIL, 1988).

8 "O status normativo supralegal dos tratados internacionais de direitos humanos subscritos pelo Brasil, dessa forma, torna inaplicável a legislação infraconstitucional com ele conflitante, seja ela anterior ou posterior ao ato de adesão" (BRASIL, 2009, p. 60).

9 Ratificada pelo Brasil em 18 de maio de 1992.
} 
Por fim, outra questão a ser considerada dentro dos pontos citados da RT é a Lei no 13.429/2017 (BRASIL, 2017b), tratando da terceirização irrestrita tanto para as atividadesmeio como para as atividades-fim. Conforme a redação do art. 4-A, §1 ${ }^{\underline{o}}$, verifica-se: “A empresa prestadora de serviços contrata, remunera e dirige o trabalho realizado por seus trabalhadores, ou subcontrata outras empresas para realização desses serviços" (BRASIL, 2017b). Logo, abrem-se precedentes para uma empresa terceirizada contratar outra empresa terceirizada e assim sucessivamente, resultando em mais desdobramentos de precarização em relação, principalmente, à qualidade do trabalho realizado e à remuneração do trabalhador.

Nesse sentido, deve-se lembrar do princípio contido na Declaração de Filadélfia, de que trabalho não é mercadoria (SCALÉRCIO; MINTO, 2016). Logo, existe uma proibição da intermediação da mão de obra. Todavia, não é o que ocorre em relação à terceirização, pois sua finalidade é mercantilizar o trabalho humano, apresentando-se como uma relação de trabalho desprovida de proteção normativa, abrindo caminho para realidades de fraude (DELGADO; DUTRA, 2018).

Do exposto, verifica-se que a terceirização é totalmente contrária ao que preceitua o trabalho digno, porquanto, em vez de destacar o valor humano do trabalhador, assegurando uma existência humana digna, o desvaloriza a tal ponto que o trabalhador chega a ser considerado como mero instrumento do sistema de necessidades do capital.

\section{Considerações finais}

Ao longo do presente texto, analisaram-se alguns dos principais aspectos da RT de 2017, tendo como eixo a precarização do trabalho no capitalismo contemporâneo, comparando-os com os elementos pertinentes à concepção de trabalho digno - fundado no princípio constitucional da dignidade da pessoa humana.

A partir da análise dos artigos 223-G; 611-A; 611-B; 582 e 507-B da Lei no 13.467/2017 (BRASIL, 2017a); e da terceirização irrestrita, da Lei no 13.429/2017 (BRASIL, 2017b), verificou-se que eles foram estabelecidos para flexibilizar e desregulamentar as leis trabalhistas, atuando em benefício da elite empresarial e sem garantias de o excedente econômico ser revertido em ampliação do mercado de trabalho ou melhorias salariais. Ademais, quando comparadas as normas à concepção de trabalho digno, identificou-se como ferem o patamar mínimo de direitos trabalhistas, proposto pelos organismos internacionais e comprometendo, assim, o valor da dignidade no trabalho e a afirmação social do trabalhador.

Nesse sentido, salienta-se que o papel do Estado quanto à regulamentação das questões do trabalho deveria ser atuar visando a melhoria das condições laborais, afinal, a dignidade da pessoa humana, prevista no art. 1º, inciso III, da CF de 1988 (BRASIL, 1988), trata-se de um valor (princípio e regra) contido na legislação brasileira e deve embasar todo o ordenamento jurídico do país (SARLET, 2015). Contrariamente a este valor, constata-se que o Estado adotou a visão utilitarista com vistas a atender as exigências do mercado, rompendo, portanto, com a diretriz protetiva que deveria orientar o Direito do Trabalho, reduzindo o sentido da dignidade da pessoa humana - inerente a qualquer tipo de labor. 
Por fim, conclui-se que a desregulamentação e flexibilização dos artigos da RT analisados compõem o desmonte de direitos laborais previstos pelo modelo neoliberal, o qual tem no trabalhador um mero instrumento que compõe o sistema de necessidades do modo capitalista de produção. Como consequência disso, têm-se as novas morfologias da precarização do trabalho.

\section{Referências}

ALVES, Giovanni. O novo (e precário) mundo do trabalho: reestruturação produtiva e a crise do sindicalismo. São Paulo: Boitempo, 2000.

ANTUNES, Ricardo. O privilégio da servidão: o novo proletariado de serviços na era digital. São Paulo: Boitempo, 2018.

ANTUNES, Ricardo; PRAUN, Luci. A sociedade dos adoecimentos no trabalho. Serv. Soc. Soc., São Paulo, n. 123, p. 407-427, jul./set. 2015. Disponível em: http://www.scielo.br/scielo.php?script=sci_arttext\&pid=So10166282015000300407\&lng=pt\&tlng=pt. Acesso em: 11 set. 2019.

BRAGA, Ruy. A rebeldia do precariado: trabalho e neoliberalismo no Sul global. São Paulo: Boitempo, 2017.

BRASIL. Constituição (1988). Constituição da República Federativa do Brasil. Brasília (DF): Senado Federal: Centro Gráfico, 1988. Disponível em:

http://www.planalto.gov.br/ccivil_03/constituicao/constituicao.htm. Acesso em: 11 set. 2020.

BRASIL. Presidência da República. Lei no 13.467, de 13 de julho de 2017. Altera a Consolidação das Leis do Trabalho (CLT), aprovada pelo Decreto-Lei no 5.452, de 10 de maio de 1943, e as Leis nos 6.019, de 3 de janeiro de 1974, 8.036, de 11 de maio de 1990, e 8.212, de 24 de julho de 1991, a fim de adequar a legislação às novas relações de trabalho. Brasília (DF), 2017a. Disponível em: http://www.planalto.gov.br/ccivil_03/_ato20152018/2017/lei/l13467.htm. Acesso em: 11 set. 2020.

BRASIL. Presidência da República. Lei no 13.429, de 31 de março de 2017. Altera dispositivos da Lei n o 6.019, de 3 de janeiro de 1974, que dispõe sobre o trabalho temporário nas empresas urbanas e dá outras providências; e dispõe sobre as relações de trabalho na empresa de prestação de serviços a terceiros. Brasília (DF), 2017b. Disponível em: http://www.planalto.gov.br/ccivil_03/_ato2015-2018/2017/lei/l13429.htm. Acesso em: 11 set. 2020.

BRASIL. Supremo Tribunal Federal. Recurso Extraordinário no 466343 / SP - SÃO PAULO. Relator: Min. Cezar Peluso. DJ, 3 dez. 20o8. Diário da Justiça Eletrônico, 5 jun. 2009.

CARVALHO, Sandro Sacchet de. Uma visão geral sobre a reforma trabalhista. Mercado de trabalho: conjuntura e análise, Brasília (DF), n. 63, p. 81-94, out. 2017. Disponível em: http://repositorio.ipea.gov.br/handle/11058/8130. Acesso em: 4 set. 2019. 
CHADE, Jamil. Em resposta dura, governo Bolsonaro critica OIT. Uol Notícias, 7 jun. 2019. Disponível em: https://jamilchade.blogosfera.uol.com.br/2019/o6/o7/em-resposta-duragoverno-bolsonaro-critica-oit/. Acesso em: 13 out. 2020.

CHESNAIS, François. O capital portador de juros: acumulação, internacionalização, efeitos econômicos e políticos. In: CHESNAIS, François (org.). A finança mundializada. São Paulo: Boitempo, 2005.

COUTINHO, Maria Luiza Pinheiro. Discriminação no trabalho: mecanismos de combate à discriminação e promoção de igualdade de oportunidades. Brasília (DF): OIT, 2006.

DELGADO, Gabriela Neves. Direito fundamental ao Trabalho Digno. 2. ed. São Paulo: LTr, 2015.

DELGADO, Gabriela Neves; DUTRA, Renata Queiroz. Terceirização sem limites: crônica de uma tragédia social anunciada. Revista Magister de Direito do Trabalho, Porto Alegre, v. 87, p. 94-98, 2018.

\section{DEPARTAMENTO INTERSINDICAL DE ESTATÍSTICAS E ESTUDOS} SOCIOECONÔMICOS. A Reforma Trabalhista e os impactos para as relações de trabalho no Brasil. São Paulo: DIEESE, maio 2017. (Nota Técnica, no 178). Disponível em: https://www.dieese.org.br/notatecnica/2017/notaTec178reformaTrabalhista.pdf. Acesso em: 9 set. 2019.

DEPARTAMENTO INTERSINDICAL DE ESTATÍSTICAS E ESTUDOS SOCIOECONÔMICOS. A inserção da mulher no mercado de trabalho. Boletim Pesquisa de Emprego e Desemprego (PED), São Paulo: DIEESE, março de 2013. Disponível em: https://www.dieese.org.br/analiseped/2013/2013pedmulhermet.pdf. Acesso em: 30 maio 2020.

FILGUEIRAS, Luiz. Neoliberalismo e crise na América Latina: o caso do Brasil. Buenos Aires: CLACSO, 2003. Disponível em:

http://bibliotecavirtual.clacso.org.ar/clacso/se/20100723022522/filgueiras.pdf. Acesso em: 9 set. 2019 .

INTERNATIONAL LABOUR OFFICE (ILO). Report of the Committee of Experts on the Application of Conventions and Recommendations. REPORT III (Part A). 107th Session. Genebra: International Labour Conference, 2018. Disponível em: https://www.ilo.org/wcmsp5/groups/public/---ed_norm/--relconf/documents/meetingdocument/wcms_617065.pdf. Acesso em: 13 out. 2020.

LAMEIRAS, Maria Andreia Parente; CORSEUIL, Carlos Henrique L.; RAMOS, Lauro Roberto Albrecht; CARVALHO, Sandro Sacchet de. Carta de Conjuntura, Brasília (DF): IPEA, n. 43, $2^{\circ}$ trimestre 2019. Seção VIII Mercado de Trabalho. Disponível em:

http://www.ipea.gov.br/portal/images/stories/PDFs/conjuntura/190618_cc_43_mercado_de_ trabalho.pdf. Acesso em: 10 set. 2019. 
LOURENÇO, Edvânia Ângela de Souza. Reforma Trabalhista e os seus impactos para a saúde do $\backslash a(s)$ trabalhador $\backslash a(s)$. [Entrevista cedida a] Fernando Mendonça Heck. Revista Pegada, Presidente Prudente, v. 19, n. 1, p. 258-273, jan./abr. 2018. Disponível em: http://revista.fct.unesp.br/index.php/pegada/article/view/5821/4448. Acesso em: 10 set. 2019.

MARINI, Ruy Mauro. Dialéctica de la dependencia (1973). In: América Latina, dependencia y globalización. Bogotá: Siglo del Hombre - CLACSO, 2008. Disponível em: http://bibliotecavirtual.clacso.org.ar/ar/libros/secret/critico/marini/o4dialecticaz.pdf. Acesso em: 2 out. 2020.

MARQUES, Rosa Maria; UGINO, Camila Kimie. O Brasil é chamado à ordem. Argumentum, Vitória, v. 9, n. 3, p. 8-23, set./dez. 2017. Disponível em: http://www.periodicos.ufes.br/argumentum/article/view/17944. Acesso em: 11 set. 2019.

MÉSZÁROS, István. Para além do capital. São Paulo: Boitempo, 2002.

OLIVEIRA, Mariana; D’AGOSTINO, Rosanne. OIT mantém Brasil em lista de países monitorados e pede dados sobre reforma trabalhista. G1, Brasília(DF) , 19 jun. 2019. Disponível em: https://g1.globo.com/politica/noticia/2019/o6/19/oit-mantem-brasil-emlista-de-paises-monitorados-e-pede-dados-sobre-reforma-trabalhista.ghtml. Acesso em: 13 out. 2020.

PEREIRA, Camila Potyara. Proteção Social em tempos sem brios. Argumentum, Vitória, v. 9, n. 3, p. 24-29, set./dez. 2017. Disponível em:

http://www.periodicos.ufes.br/argumentum/article/view/17945. Acesso em: 11 set. 2019.

RAFAGNIN, Maritânia Salete Salvi. Reflexos da reforma trabalhista para gestantes e lactantes. Argumentum, Vitória, v. 11, n. 1, p. 230-245, jan./abr. 2019. Disponível em: http://periodicos.ufes.br/argumentum/article/view/2308o. Acesso em: 11 set. 2019.

RAFAGNIN, Thiago Ribeiro. Emenda constitucional 95: do neoliberalismo à possível violação da Constituição Federal de 1988. 2019. Tese (doutorado em Política Social e Direitos Humanos) - Centro de Ciências Sociais e Tecnológicas, Universidade Católica de Pelotas, Pelotas, 2019.

ROSENFIELD, Cinara L.; PAULI, Jandir. Para além da dicotomia entre trabalho decente e trabalho digno: reconhecimento e direitos humanos. Cad. CRH, Salvador, v. 25, n. 65, p. 319329. 2012. Disponível em: http://www.scielo.br/scielo.php?pid=So10349792012000200009\&script=sci_abstract\&tlng=pt. Acesso em: 11 set. 2019.

SARLET, Ingo Wolfgang. Dignidade (da Pessoa) Humana e Direitos Fundamentais na Constituição Federal de 1988. 10. ed. Porto Alegre: Livraria do Advogado Editora, 2015.

SCALÉRCIO, Marcos; MINTO, Tulio Martinez. Normas da OIT organizadas por temas. São Paulo: LTr, 2016. 
SCHERER, Giovane Antônio; DILIGENTI, Marcos Pereira; ARAÚJO, Ricardo Souza. Direitos e (Des)Emprego: uma falsa dicotomia. Sociedade em Debate, Pelotas, v. 25, n. 2, p. 129-138, maio/ago. 2019. Disponível em:

http://revistas.ucpel.tche.br/index.php/rsd/article/view/2246. Acesso em: 11 set. 2019.

SILVA, Mauri Antonio da. Os reflexos da crise econômica sobre os direitos trabalhistas no Brasil. Katálysis, Florianópolis, v. 22, n. 2, p. 252-272, maio/ago. 2019. Disponível em: https://periodicos.ufsc.br/index.php/katalysis/article/view/1982-02592019v22n2p252. Acesso em: 25 set. 2019.

TENEMBLAT, Mably Jane Trindade. Financeirização do capital e questão social no contexto do novo-desenvolvimentismo. SER Social, Brasília (DF), v. 16, n. 35, p. 327-353, jul./dez. 2014. Disponível em: http://periodicos.unb.br/index.php/SER_Social/article/view/1340o. Acesso em: 12 set. 2019 .

Maritânia Salete Salvi RAFAGNIN Trabalhou na concepção e interpretação dos dados, na redação do artigo e na aprovação da versão a ser publicada.

Contadora. Mestra em Política Social. Doutoranda em Política Social e Direitos Humanos pela Universidade Católica de Pelotas (UCPel). Bolsista CAPES.

Vera Maria Ribeiro NOGUEIRA Trabalhou na concepção, na revisão crítica e na aprovação da versão a ser publicada.

Assistente Social. Doutora em Enfermagem. Professora do Programa de Pós-Graduação em Política Social e Direitos Humanos da Universidade Católica de Pelotas (UCPel) e do Programa de Pós-Graduação em Serviço Social da Universidade Federal de Santa Catarina (UFSC).

Argum., Vitória, v. 13, n. 1, p. 153-166, jan./abr. 2021. | ISSN 2176-9575 